\title{
Study on the Grindability Ranking of Granite Using Fuzzy Analytical Hierarchy Process and TOPSIS Approaches
}

\author{
Zhengmei Zhang ${ }^{1, a}$, Baoliang Xing ${ }^{1, b}$, Shaohua $\mathrm{Li}^{1, \mathrm{c}}$, Huiying Cao ${ }^{1, \mathrm{~d}}$ and \\ Shuqin Zhang ${ }^{1, \mathrm{e}}$, \\ ${ }^{1}$ Shandong Labor Vocational and Technology College, Jinan 250022, China \\ azmzhang907@163.com, bxbl-19690504@163.com, 'lishaohua@sdlvtc.cn, \\ dcaohuiying2012@126.com, ${ }^{\mathrm{e}}$ zhangshuqin@sdlvtc.cn
}

Keywords: Grindability, Granite, Grinding force, FAHP, TOPSIS

Abstract. The ranking system of granite grindability is very important for high-efficiency grinding key technology. A new method by the combination of Fuzzy Analytic Hierarchy Process (FAHP) method with TOPSIS methods is developed to establish the dependence function and fuzzy relationship. The grindability of ten types of granite was evaluated and classified by this method. With the fuzzy ranking system established and the grindability classification, it is very convenient to evaluate the grindability and select a suitable diamond tool and proper grinding parameters for a new granite type by only the petrographic analysis and mechanical properties testing.

\section{Introduction}

The granite is a natural rock material that consist of several minerals, so the grindability of different types of granite is different. The ranking system of granite grindability is very important for high-efficiency grinding key technology. Many experts have been studied the sawability of granites and tried to conceive the ranking method for granites. Reza Mikaeil proposed changes of motor power while cutting stone to stone sawing performance evaluation [1,2]. Saffet Yagiz proposed to evaluate the brittleness of stone sawing of stone, and the use of fuzzy inference system and nonlinear regression to establish a mathematical model of sawing force [3]. Bulent Tiryaki used the specific cutting energy index to evaluate the machinability of the stone, and using artificial neural network prediction model [4]. The aim of this paper is developing a new method by the combination of Fuzzy Analytic Hierarchy Process (FAHP) method with TOPSIS (Technique for Order Preference by Similarity to Ideal Solution) methods.

\section{Applied theoretical concept}

Thoery of Triangular Fuzzy. In this study, the FAHP is used. Let $X=\left\{x_{1}, x_{2}, x_{3} \mathrm{~L}, x_{n}\right\}$ be an object set, and $G=\left\{g_{1}, g_{2}, g_{3} \mathrm{~L}, g_{n}\right\}$ be a goal set, each object is taken, and extent analysis for each goal performed respectively. Therefore, $m$ extent analysis values for each object can be obtained with $M_{g i}^{1}, M_{g i}^{2}, \ldots, M_{g i}^{m}(i=1,2, \ldots, n)$, where $M_{g i}^{j}(j=1,2, \mathrm{~L}, m)$ all are triangular fuzzy numbers(TFN). The steps of extent analysis can be given as in the following:

Step 1 . The value of fuzzy synthetic extent with respect to the $i$ object is defined as

$$
S_{i}=\sum_{j}^{m} M_{g i}^{j} \otimes\left[\sum_{i=1}^{n} \sum_{j=1}^{m} M_{g i}^{j}\right]^{-1}
$$

To obtain $\sum_{j=1}^{m} M_{g i}^{j}$, the fuzzy addition operation of $m$ extent analysis values for a particular matrix is performed as follows $\sum_{j}^{m} M_{g i}^{j}=\left(\sum_{j=1}^{m} l_{j}, \sum_{j=1}^{m} m_{j}, \sum_{j=1}^{m} u_{j}\right), \sum_{i=1}^{n} \sum_{j=1}^{m} M_{g i}^{j}=\left(\sum_{i=1}^{n} l_{i}, \sum_{i=1}^{n} m_{i}, \sum_{i=1}^{n} u_{i}\right)$, 


$$
\left[\sum_{i=1}^{n} \sum_{j=1}^{m} M_{g i}^{j}\right]^{-1}=\left(\frac{1}{\sum_{i=1}^{n} u_{i}}, \frac{1}{\sum_{i=1}^{n} m_{i}}, \frac{1}{\sum_{i=1}^{n} l_{i}}\right) .
$$

Step 2. As $M_{1}\left(l_{1}, m_{1}, u_{1}\right)$ and $M_{2}\left(l_{2}, m_{2}, u_{2}\right)$ are two triangular fuzzy numbers, the degree of possibility of $M_{1} \geq M_{2}$ is defined as

$$
V\left(M_{1} \geq M_{2}\right)=\sup _{x \geq y}\left[\min \left(\mu_{M_{1}}(x), \mu_{M 2}(y)\right)\right]
$$

and can be expressed as follows

$$
V\left(M_{1} \geq M_{2}\right)=\mu(d)= \begin{cases}1, & m_{1} \geq m_{2} \\ \frac{l_{2}-u_{1}}{\left(m_{1}-u_{1}\right)-\left(m_{2}-l_{2}\right)}, & m_{1} \leq m_{2}, \quad u_{1} \geq l_{2} \\ 0, & \text { otherwise }\end{cases}
$$

Step 3. The degree of possibility for a convex fuzzy number to be greater than $\mathrm{k}$ convex fuzzy $M_{i}(i=1,2, \ldots, \mathrm{k})$ numbers can be defined by

$$
V\left(M \geq M_{1}, M_{2}, \mathrm{~L} \mathrm{~L} M_{k}\right)=\min V\left(M \geq M_{i}\right), i=1,2, \mathrm{~L} k
$$

Assume that $d^{\prime}\left(A_{i}\right)=\min V\left(S_{i} \geq S_{k}\right) \quad(k=1,2, \mathrm{~L} m, k \neq i)$, then the weight vector is given by

$$
W^{\prime}=\left(d^{\prime}\left(A_{1}\right), d^{\prime}\left(A_{2}\right), \mathrm{L}, d^{\prime}\left(A_{m}\right)\right)^{T}
$$

Where $A_{i}(i=1,2, \ldots, n)$ are $i$ elements.

Step 4. Via normalization, the normalized weight vectors are

$$
W=\left(d\left(A_{1}\right), d\left(A_{2}\right), \mathrm{L}, d\left(A_{m}\right)\right)^{T}
$$

where $W$ is a non-fuzzy number.

TOPSIS method. TOPSIS is one of the useful multi-attribute decision making techniques to manage real-world problems. In this paper, TOPSIS method is used for determining the final ranking of the sawability of granites. TOPSIS method is performed in the following steps:

Step 1. Decision matrix is normalized via Eq. (7)

$$
r_{i j}=\frac{f_{i j}}{\sqrt{\sum_{i=1}^{n} f_{i j}^{2}}} \quad i=1,2, \mathrm{~L} n ; j=1,2, \mathrm{~L}, m
$$

Step 2. Weighted normalized decision matrix is formed

$$
v_{i j}=W_{j} \times r_{i j} \quad i=1,2, \mathrm{~L} n ; j=1,2, \mathrm{~L}, m
$$

Step 3. Positive Ideal Solution and Negative Ideal Solution are determined

$$
\begin{aligned}
& A^{+}=\left\{v_{1}^{+}, v_{2}^{+}, v_{3}^{+}, \mathrm{L}, v_{m}^{+}\right\}^{T}, v_{j}^{+}=\max _{i}\left\{v_{i j}\right\}, j=1,2, \mathrm{~L}, m \\
& A^{-}=\left\{v_{1}^{-}, v_{2}^{-}, v_{3}^{-}, \mathrm{L}, v_{m}^{-}\right\}^{T}, v_{j}^{-}=\min _{i}\left\{v_{i j}\right\}, j=1,2, \mathrm{~L}, m
\end{aligned}
$$

Step 4 . The distance of each alternative from $A^{+}$and $A^{-}$are calculated

$$
D_{i}^{+}=\sqrt{\sum_{i=1}^{n}\left(v_{j}^{+}-v_{i j}\right)^{2}} \quad D_{i}^{-}=\sqrt{\sum_{i=1}^{n}\left(v_{j}^{-}-v_{i j}\right)^{2}}
$$


Step 5. The closeness coefficient of each alternative is calculated

$C_{i}=\frac{D_{i}^{-}}{D_{i}^{+}+D_{i}^{-}} \quad 0 \leq C_{\mathrm{i}} \leq 1$

Step6. By comparing $C_{i}$ values, the ranking of alternatives are determined.

\section{Application of FAHP-TOPSIS Method to Multi-criteria Comparison of Grindability}

Granite Materials and Parameters. Test workpieces are selected typical granite materials. The $\mathrm{SiO}_{2}$ content, quartz content, Shore hardness, density, compressive strength, flexural strength and abrasion resistance are as the most granite important characteristics that affect grindability. In order to get the universal research conclusion, Ten kinds of granite that widely used are choosen to experiment. these parameters are shown in Table 1.

Table 1 Material parameters of granites

\begin{tabular}{lccccccc}
\hline \multirow{2}{*}{ Granite type } & $\begin{array}{c}\mathrm{SiO}_{2} \\
{[\%]}\end{array}$ & $\begin{array}{c}\text { Quartz } \\
\text { content } \\
{[\%]}\end{array}$ & $\begin{array}{c}\text { Shore } \\
\text { hardness } \\
{[\mathrm{HSD}]}\end{array}$ & $\begin{array}{c}\text { Density } \\
{\left[\mathrm{g} \cdot \mathrm{cm}^{-3}\right]}\end{array}$ & $\begin{array}{c}\text { Compressive } \\
\text { strength } \\
{[\mathrm{MPa}]}\end{array}$ & $\begin{array}{c}\text { Flexural Abrasion } \\
\text { strength resistance } \\
{[\mathrm{MPa}]}\end{array}$ & {$\left[\mathrm{g} \cdot \mathrm{cm}^{-2}\right]$} \\
\hline Wulian Red & 67.55 & 24.3 & 85 & 2.68 & 92.89 & 8.542 & 0.6 \\
Cherry Blossom Red & 75.25 & 45.06 & 104 & 2.58 & 149.9 & 14.1 & 2.572 \\
Shidao Red & 64.29 & 44.19 & 110 & 2.7 & 234.37 & 13.63 & 2.68 \\
Qilu Red & 69.01 & 29.7 & 87 & 2.661 & 162 & 13.97 & 3.822 \\
Liubu Red & 75.64 & 43.36 & 60.4 & 2.61 & 203.97 & 20.89 & 1.607 \\
Laoshan Red & 71.88 & 29.76 & 99.7 & 2.59 & 208.29 & 18.06 & 3.828 \\
Lu Grey & 67.25 & 47.11 & 104 & 2.58 & 149.9 & 14.1 & 2.735 \\
Marshal Red & 70.22 & 25.2 & 90 & 2.65 & 147.88 & 12.87 & 3.76 \\
China Grey & 70.19 & 38.41 & 115 & 2.65 & 214.40 & 15.00 & 3.036 \\
Wulian Flower & 62.28 & 22 & 85 & 2.65 & 90.77 & 8.35 & 5.473 \\
\hline Determination
\end{tabular}

Determination of Criteria Weights. The fuzzy judgment matrix is established about $\mathrm{SiO}_{2}$ content(C1), quartz content(C2), Shore hardness(C3), density(C4), compressive strength(C5), flexural strength(C6) and abrasion resistance(C7) using pair-wise comparison. According to the grinding process goal of granite, the weights for the parameters of granites are analyzed. A comprehensive triangular fuzzy pair-wise comparison matrix is built as in Table 2 .

Table 2 Triangular fuzzy pair-wise comparison matrix

\begin{tabular}{|c|c|c|c|c|c|c|c|}
\hline & $\mathrm{C} 1$ & $\mathrm{C} 2$ & $\mathrm{C} 3$ & $\mathrm{C} 4$ & C5 & C6 & $\mathrm{C} 7$ \\
\hline $\mathrm{C} 1$ & $(1,1,1)$ & $(1 / 5,1 / 4,1 / 3)$ & $(1,2,3)$ & $\begin{array}{c}(3,4 \\
5)\end{array}$ & $(1 / 4,1 / 3,1 / 2)$ & $(1 / 3,1 / 2,1)$ & $(2,3,4)$ \\
\hline $\mathrm{C} 2$ & $(3,4,5)$ & $(1,1,1)$ & $(4,5,6)$ & $\begin{array}{c}(6,7, \\
8)\end{array}$ & $(1,2,3)$ & $(2,3,4)$ & $(5,6,7)$ \\
\hline C3 & $(1 / 3,1 / 2,1)$ & $(1 / 6,1 / 5,1 / 4)$ & $(1,1,1)$ & $\begin{array}{c}(2,3, \\
4)\end{array}$ & $(1 / 5,1 / 4,1 / 3)$ & $(1 / 4,1 / 3,1 / 2)$ & $(1,2,3)$ \\
\hline $\mathrm{C} 4$ & $(1 / 5,1 / 4,1 / 3)$ & $(1 / 8,1 / 7,1 / 6)$ & $(1 / 4,1 / 3,1 / 2)$ & $\begin{array}{c}(1,1, \\
1)\end{array}$ & $(1 / 7,1 / 6,1 / 5)$ & $(1 / 6,1 / 5,1 / 4)$ & $(1 / 3,1 / 2,1)$ \\
\hline $\mathrm{C} 5$ & $(2,3,4)$ & $(1 / 3,1 / 2,1)$ & $(3,4,5)$ & $\begin{array}{c}(5,6, \\
7)\end{array}$ & $(1,1,1)$ & $(1,2,3)$ & $(4,5,6)$ \\
\hline C6 & $(1,2,3)$ & $(1 / 4,1 / 3,1 / 2)$ & $(2,3,4)$ & $\begin{array}{c}(4,5, \\
6)\end{array}$ & $(1 / 3,1 / 2,1)$ & $(1,1,1)$ & $(3,4,5)$ \\
\hline $\mathrm{C} 7$ & $(1 / 4,1 / 3,1 / 2)$ & $(1 / 7,1 / 6,1 / 5)$ & $(1 / 3,1 / 2,1)$ & $\begin{array}{c}(1,2, \\
3)\end{array}$ & $(1 / 6,1 / 5,1 / 4)$ & $(1 / 5,1 / 4,1 / 3)$ & $(1,1,1)$ \\
\hline
\end{tabular}


Table 3 Results of priority weights and standardized weights

\begin{tabular}{cccccccc}
\hline & C1 & C2 & C3 & C4 & C5 & C6 & C7 \\
\hline Priority weights & 0.1301 & 1 & 0 & 0 & 0.7427 & 0.4533 & 0 \\
Standardized weights & 0.0559 & 0.4299 & 0 & 0 & 0.3193 & 0.1949 & 0
\end{tabular}

The triangular fuzzy synthesis values $S_{i}$ are calculated by using Eq. (1), The fuzzy values are compared by using Eq. (3), and the values of $V$ are obtained. Then, priority weights are calculated by using Eq. (4). After normalizing the priority weights the standardized weights are extracted, the results of priority weights and standardized weights are shown in table 3.

Ranking the grindability of granite. The weights of $\mathrm{C} 3, \mathrm{C} 4$ and $\mathrm{C} 7$ are zero from table 3, it means that these parameters are nonobviously to affect the grindability of granite. The greatest significance parameters of $\mathrm{C} 1, \mathrm{C} 2, \mathrm{C} 5$ and $\mathrm{C} 6$ are selected to rank the grindability of granite. Decision matrix is normalized via Eq. (7) and weighted normalized decision matrix is formed by using Eq. (8). Positive and negative ideal solutions are determined by taking the maximum and minimum values for each criterion via Eqs. (9) and (10):

$A^{+}=\{0.0192,0.1735,0.1376,0.0894\}, A^{-}=\{0.0158,0.0810,0.0533,0.0357\}$.

Then, the distance of each method from PIS (positive ideal solution) and NIS (negative ideal solution) with respect to each criterion are calculated, with the help of Eq. (11). Then, closeness coefficient of each granite is calculated by using Eq. (12) and the ranking of the granites are determined according to these values. The grindability ranking of granites are also shown in table 4 .

Table 4 Rankings of the grindability of granites according to $C_{i}$ values

\begin{tabular}{lcccc}
\hline \multicolumn{1}{c}{ Granite type } & $D^{+}$ & $D^{-}$ & $C_{i}$ & Rank \\
\hline Wulian Red & 0.1092 & 0.0454 & 0.2936 & 8 \\
Cherry Blossom Red & 0.0580 & 0.0951 & 0.6213 & 5 \\
Shidao Red & 0.0330 & 0.1196 & 0.7838 & 2 \\
Qilu Red & 0.0824 & 0.0560 & 0.4046 & 7 \\
Liubu Red & 0.0226 & 0.1162 & 0.8375 & 1 \\
Laoshan Red & 0.0668 & 0.0855 & 0.5614 & 6 \\
Lu Grey & 0.0575 & 0.1019 & 0.6391 & 4 \\
Marshal Red & 0.1013 & 0.0405 & 0.2857 & 9 \\
China Grey & 0.0424 & 0.0987 & 0.6993 & 3 \\
Wulian Flower & 0.1362 & 0.0001 & 0.0005 & 10 \\
\hline
\end{tabular}

\section{Conclusions}

(1) The grindability is affected by the $\mathrm{SiO}_{2}$ content, quartz content, compressive strengthand flexural strength of the granite.

(2) The criteria of grindability is affected by the above-mentioned factors in a different trend. So, the rights of the factors are distributed in different ways for evaluating the grindability using different criteria.

(3) This new ranking method of granite grindability by means of fuzzy mathematics is reasonable and acceptable. For evaluating the grindability of a new granite type, only the petrographic analysis and mechanical property testing instead of a number of grinding tests are needed to obtain the information about the grindability prediction.

\section{Acknowledgements}

The research was financially supported by the Science and Technology Foundation of Shandong Labor Vocational and Technology College (Grant No. 2015KJZ003). 


\section{References}

[1] Reza Mikaeil, Reza Yousefi: Scientia Iranica B. Forum Vol. 18 (2011), p. 1106-1115.

[2] Mikaeil Reza, Ataei Mohammad, Yousefi Reza: Mining Science and Technology. Forum Vol. 21 (2011), p. 611-619.

[3] Saffet Yagiz, Candan Gokceoglu: Expert Systems with Applications. Forum Vol. 37 (2010), p. 2266-2272.

[4] Bulent Tiryaki: Engineering Geology. Forum Vol. 99 (2008), p. 51-60. 